Artículos

\title{
Protagonistas de la investigación educativa. Investigador-investigado en construcción recíproca
}

The protagonists of educational research. Researcher-researched in reciprocal construction

Leticia Pons Bonals

DOI: https://doi.org/10.24215/18537863e068

Universidad Autónoma de Querétaro, México

pbonals@hotmail.com

Iván de Jesús Espinosa Torres

Instituto de Estudios de Posgrado de Chiapas, México

ivandejesuset@hotmail.com

Recepción: 12 Junio 2019

Aprobación: 28 Noviembre 2019

\section{RESUMEN:}

El ensayo aborda las relaciones entre investigador e investigado. Recupera planteamientos de diversos autores que asumen posiciones no positivistas proponiendo el término coinvestigador para referirse a las personas que acompañan a quien investiga durante el proceso de indagación, compartiendo y reflexionando acerca de sus experiencias de vida. Se revisan distintos paradigmas o tradiciones de investigación y se recuperan planteamientos teórico-metodológicos de la hermenéutica, autoetnografía, investigación narrativa, investigación-acción, pensamiento posmoderno y decolonialidad para colocar al investigado como productor de conocimiento que influye la investigación. Se concluye enfatizando en la reflexividad y los compromisos que entraña la relación investigador-investigado.

Palabras Clave: Investigador, Investigado, Investigación educativa, Paradigmas de investigación, Tradiciones de investigación.

\section{Abstract:}

The discussion begins by reviewing the different paradigms or research traditions. Subsequently, the authors draw from theoreticalmethodological approaches - such as hermeneutics, self-ethnography, narrative research, action research, postmodern thought, and decolonial theory - to place the researcher as a producer of knowledge whose position influences the research itself. The conclusions emphasize the role played by reflexivity and commitment in the relationship researcher-researched. Key words: Researcher - Researched subject - Educational research - Research paradigms - Research traditions Introducción

KEYWORDS: Researcher, Researched subject, Educational research, Research paradigms, Research traditions.

\section{INTRODUCCIÓN}

El propósito de este artículo es contribuir al debate sobre uno de los criterios de demarcación del conocimiento científico que se confronta entre diversos paradigmas o tradiciones del campo de la investigación educativa; nos referimos a la relación que se establece entre investigador e investigado. Aludimos aquí a la investigación educativa como aquella que posibilita la comprensión, explicación, interpretación y/o transformación del fenómeno educativo (según sea la perspectiva paradigmática de quien indaga) en contextos regionales específicos caracterizados por elementos sociales, culturales, políticos, históricos, económicos y geográficos que los conforman y distinguen. Los procesos de investigación se enmarcan en derroteros técnicos-instrumentales, teóricos, metodológicos, epistemológicos, filosóficos y ontológicos que de forma consciente o inconsciente el investigador construye en su relación con los investigados. 
Uno de los fines últimos de la investigación educativa es la construcción de conocimientos que posibiliten encontrar nuevas concepciones y significados para la atención de los problemas educativos en contextos específicos; esta concepción desborda las miradas limitadas a lo escolar y reconoce una multiplicidad de contextos formativos en los que los sujetos se educan. La complejidad para estudiar las realidades educativas exige transitar hacia perspectivas interdisciplinares y transdisciplinares; también permite reconocer los orígenes de la investigación educativa en las ciencias sociales y humanas, así como su íntima relación y familiaridad con algunos de sus posicionamientos y procedimientos. Por esta razón, a lo largo del escrito el lector puede encontrar elementos que reconocerá como no exclusivos de la investigación educativa.

Se sostiene que en la investigación educativa -cuyo punto de partida es la comprensión de los procesos formativos que llevan a las personas a crear o recrear sentidos y significados, así como a promover prácticas que inciden en su vida cotidiana- la intersubjetividad que marca la relación investigador e investigado conlleva un proceso de (re)construcción recíproca. Por ello se propone el uso del término coinvestigador para hacer referencia a las personas que acompañan al investigador durante el proceso de indagación, compartiendo y reflexionando acerca de sus experiencias de vida. Lo expresado antes es pertinente porque se sostiene que esta actuación no se limita a proveer información, sino que implica dialogar, compartir y aportar elementos que permiten reconstruir los propósitos y caminos que sigue el investigador, e incluso lo llevan a reconsiderar supuestos, posiciones y actitudes que asume frente a la investigación.

Para ahondar en este planteamiento, en el primer apartado se revisa el papel que se asigna al investigador en distintos paradigmas o tradiciones de investigación educativa, con la finalidad de ubicar la propuesta en aquellos que se alejan de modelos positivistas que siguen una lógica empírico-analítica.

En el segundo apartado de este artículo, Cómo ser y estar en la investigación, se recuperan algunos planteamientos teórico-metodológicos en los que se destaca la influencia recíproca entre investigador e investigado. Estos planteamientos provienen de distintos posicionamientos teórico-metodológicos como son la hermenéutica, la autoetnografía, la investigación narrativa, la investigación-acción, el pensamiento posmoderno y el pensamiento decolonial. Estos tienen en común el alejamiento de la tradición empírico-analítica, para ubicarse en paradigmas o tradiciones de investigación que comparten estrategias metodológicas que permiten asumir la denominación de coinvestigadores a cambio de otras como objetos, sujetos, informantes, participantes, e incluso colaboradores. Todas estas denominaciones tienden a ser de uso común e indistinto en diversos trabajos académicos.

En la tercera parte del artículo se precisa la definición de coinvestigadores, como la forma propuesta para nombrar la relación profunda, dialógica y dialéctica, incluso afectiva, que establece el investigador con el investigado. Estos se influyen de manera recíproca para hacer posibles las investigaciones educativas, que requieren de un componente fuerte de reflexividad y del establecimiento de compromisos, entre los cuales destaca la presentación de los resultados en formatos que resulten útiles para quienes se involucran en los procesos de generación de conocimiento, procesos que deben superar miradas y acciones simplistas.

Conviene aclarar que somos conscientes de las controversias generadas en torno a la utilización del término paradigma en ciencias sociales a partir de la definición propuesta por Kuhn (2004) en su libro La estructura de las revoluciones cientificas, de 1962 -así como las que se derivan de la corrección que el mismo autor realizara siete años después en su Posdata-. Además, si se tiene en cuenta que no es nuestro propósito centrarnos en ese debate (ver para esto Acosta, 2005; González, 2005; Pons y Hernández, 2012), en este trabajo optaremos por la utilización indistinta del concepto paradigma o tradición para referirnos a la forma compartida por una comunidad académica, inserta en un campo de conocimiento particular (en este caso el de investigación educativa), para articular en el proceso de investigación los principios ontológicos, epistemológicos, teóricos, metodológicos, técnicos e instrumentales que tienen como base, para delimitar o construir problemas, objetos de investigación, conceptos, métodos que validan el conocimiento producido y las explicaciones que resultan de su aplicación, así como las soluciones que conciben pertinentes en un contexto sociohistórico particular. 


\section{El PAPEL DEL INVESTIGADOR EN LOS PARADIGMAS DE INVESTIGACIÓN EDUCATIVA}

En el campo de la investigación educativa existe cierto consenso que identifica la coexistencia de diversos paradigmas o tradiciones (Sandín, 2004), entre los que destacan los siguientes:

1. Empírico-analítico, positivista, neopositivista, pospositivista

2. Interpretativo, hermenéutico, fenomenológico, naturalista, constructivista

3. Crítico o sociocrítico

A pesar de que no hay un acuerdo sobre la denominación precisa de cada uno de estos, pueden identificarse distintas rutas de investigación, trazadas a partir de la relación particular que se establece entre investigador e investigado. Esta relación empieza por la separación necesaria que plantea una investigación de corte positivista sustentada en la neutralidad y objetividad científicas, pasa por la empatía que propone un estudio interpretativo, y llega hasta el involucramiento del investigador como un actor más en el grupo investigado, con el que comparte intereses y posicionamientos político-ideológicos, a la manera en que lo plantea una indagación sociocrítica o participativa.

Es necesario aclarar que la relación que establece el investigador frente a aquellos a quienes investiga, o con quienes investiga, se corresponde con los posicionamientos ontológicos, epistemológicos, axiológicos y metodológicos que asume, los cuales, articulados entre sí, lo ubican en una u otra tradición de investigación. En última instancia son los intereses que guían el conocimiento los que definen la articulación de los distintos planos que se involucran, desde el planteamiento o construcción del problema hasta el establecimiento de los resultados. Estos intereses, los cuales Habermas (1990) identificó como técnicos, prácticos o emancipadores en su obra Conocimiento e interés, de 1968, han sido recuperados para sustentar la clasificación de los paradigmas a partir de los fines de la investigación: el control de la realidad, que se corresponde con el interés técnico que persigue el paradigma positivista; la comprensión de motivos y condiciones presentes en la realidad que viven los actores, que se corresponde con el interés práctico que persigue el paradigma interpretativo; la transformación de las relaciones de poder y la crítica social, que se corresponden con el interés emancipador que promueve el paradigma sociocrítico (Pons y Hernández, 2012).

La historia de la investigación educativa muestra que por mucho tiempo la tradición empírico-analítica hegemonizó la producción de conocimientos. Sin embargo, los giros deconstructivo e interpretativo, que ocurren durante la segunda mitad del siglo XX, trastocan las estructuras de las ciencias sociales en general y dan un vuelco a los procesos de generación de conocimientos sobre la educación, abriendo nuevos cuestionamientos sobre los criterios de demarcación científica. Para las décadas de 1980 y 1990 se advertía ya "el marcado cambio de las ciencias sociales hacia prácticas y formulaciones de teorías más interpretativas, posmodernas y críticas" (Bloland 1989 y 1995 citado en Guba y Lincoln, 2012).

Guba y Lincoln (2012) presentan una clasificación en la que el positivismo se desdobla en dos versiones, positivista y pospositivista, que atiende a los avances que en materia de discusiones epistemológicas marcó el paso de la versión clásica a las versiones corregidas, como producto de los debates del círculo de Viena con Karl Popper. Frente a estos dos, a los que consideran paradigmas convencionales, modernos o tradicionales, emergen los paradigmas nombrados por estos autores como posmodernos: teoría crítica y constructivismo.

Estos mismos autores proponen la inclusión de un quinto paradigma, el participativo (tradición participativa), recuperado de la propuesta de Heron y Reason de 1997, que se sumaría a los paradigmas posmodernos (ver Tabla 1). Afirman que:

los diversos paradigmas están comenzando a cruzarse de modo que dos teóricos antes considerados en conflicto irreconciliable ahora pueden aparecer bajo un epígrafe teórico diferente, enunciando uno los argumentos del otro (...) Por consiguiente, es probable que sostener que los paradigmas están en disputa sea menos útil que indagar dónde y cómo estos confluyen, y dónde y cómo presentan diferencias, controversias y contradicciones (Guba y Lincoln, 2012, p. 39). 
Tabla 1. Relación investigador e investigado en las tradiciones de investigación educativa

\begin{tabular}{|c|c|c|c|c|}
\hline PARADIG-MA & Koetting $(1984)^{*}$ & $\begin{array}{l}\text { Latorre, et al. } \\
(1996)^{*}\end{array}$ & $\begin{array}{l}\text { Lincoln y Guba } \\
(2000)^{* \star}\end{array}$ & Gubay Lincoln $(2012)^{\star \star}$ \\
\hline \multirow[b]{2}{*}{ Empírico-analítico } & \multirow{2}{*}{$\begin{array}{l}\text { Relación } \\
\text { independiente } \\
\text { entre investigador } \\
\text { e investigado (el } \\
\text { investigador } \\
\text { mantiene } \\
\text { distancia y se } \\
\text { presenta como } \\
\text { neutral) } \\
\text { Muestral } \\
\text { Libre de valores }\end{array}$} & \multirow{2}{*}{$\begin{array}{l}\text { Independencia } \\
\text { Neutralidad } \\
\text { No se afectan } \\
\text { Investigador } \\
\text { externo } \\
\text { Sujeto como } \\
\text { objeto de } \\
\text { investigación }\end{array}$} & $\begin{array}{l}\text { Positivismo: } \\
\text { Dualista/ } \\
\text { objetivista } \\
\text { (hallazgos } \\
\text { verdaderos) }\end{array}$ & \multirow{2}{*}{$\begin{array}{l}\text { Cientifico desinteresado en establecer } \\
\text { relación cercana con el investigado } \\
\text { Como informante de los encargados de } \\
\text { tomar, formular politicas y agentes del } \\
\text { cambio }\end{array}$} \\
\hline & & & $\begin{array}{l}\text { Pospositivismo: } \\
\text { Dualista/ } \\
\text { objetivista } \\
\text { modificada } \\
\text { (hallazgos } \\
\text { probablemente } \\
\text { verdaderos }\end{array}$ & \\
\hline Interpretativo & \begin{tabular}{l|} 
Interrelación \\
entre investigador \\
e investigado (el \\
investigador \\
genera empatia) \\
Relaciones \\
influidas por \\
factores \\
subjetivos
\end{tabular} & $\begin{array}{l}\text { Dependencia } \\
\text { Se afectan } \\
\text { Implicación } \\
\text { investigador } \\
\text { Interrelación }\end{array}$ & $\begin{array}{l}\text { Interactiva/ } \\
\text { subjetivista }\end{array}$ & $\begin{array}{l}\text { Participación apasionada del } \\
\text { investigador en la relación que establece } \\
\text { con el investigado } \\
\text { Investigador facilitador de la } \\
\text { reconstrucción multivocal }\end{array}$ \\
\hline Socio-critico & $\begin{array}{l}\text { Interrelacionados } \\
\text { Relaciones } \\
\text { influenciadas por } \\
\text { fuerte } \\
\text { compromiso para } \\
\text { la liberación } \\
\text { humana (el } \\
\text { investigador } \\
\text { comparte } \\
\text { intereses con los } \\
\text { investigados) }\end{array}$ & $\begin{array}{l}\text { Relación influida } \\
\text { por el } \\
\text { compromiso } \\
\text { El investigador es } \\
\text { un sujeto más }\end{array}$ & $\begin{array}{l}\text { Interactiva/ } \\
\text { subjetivista }\end{array}$ & $\begin{array}{l}\text { Intelectual transformador } \\
\text { Como defensor y activista }\end{array}$ \\
\hline Participativo & & & $\begin{array}{l}\text { Subjetividad } \\
\text { critica } \\
\text { El investigador } \\
\text { como voz } \\
\text { principal que se } \\
\text { manifiesta a } \\
\text { traves de la } \\
\text { conciencia de la } \\
\text { acción } \\
\text { reflexionada } \\
\text { Voces } \\
\text { secundarias en } \\
\text { teoria, narrativa, } \\
\text { movimiento, } \\
\text { canción, danza y } \\
\text { otras }\end{array}$ & $\begin{array}{l}\text { El investigador manifiesta la voz primaria } \\
\text { mediante la acción autorreflexiva } \\
\text { consciente } \\
\text { Voces secundarias en teoria iluminadora, } \\
\text { narrativa, movimiento, canto, baile y } \\
\text { otras formas presentacionales }\end{array}$ \\
\hline
\end{tabular}

Fuente: Elaborada a partir de los esquemas presentados por Sandín* (2004, pp. 33-34) y por Guba y Lincoln** (2012, pp. 38-78).

Si nos ubicamos en la propuesta por estos autores de encontrar puntos de confluencia entre los paradigmas, pensamos que los denominados por ellos como posmodernos (interpretativo, sociocrítico y participativo) comparten orientaciones epistemológicas y metodológicas en las cuales se replantea la manera en que el investigador reconoce y se relaciona con las personas que se involucran en el proceso de investigación; aquellas a las que quiere entender o con las que considera necesario dialogar, debatir, actuar. En estos paradigmas es posible pensar en la noción de coinvestigadores para aludir a la participación y papel que ellas representan.

Interdependencia, interrelación, interacción, subjetividad, participación son los términos que se leen en las definiciones de la relación investigador e investigado en los paradigmas interpretativo y sociocrítico; reflexión, autorreflexión, voces son los términos que se destacan para caracterizar esta relación en el paradigma participativo. En los tres paradigmas podemos encontrar una confluencia: la implicación del investigador. Esta es una diferencia clara que se opone a la postura positivista (en su versión clásica y su versión 
pospositivista), en donde la separación investigador e investigado es condición para el logro de la verdad y la objetividad.

En la investigación educativa, además de la propuesta de incorporación del paradigma participativo a los tres paradigmas ya reconocidos (positivista, interpretativo y sociocrítico), se encuentra la propuesta de Lather (citado en Sandín, 2004) de otro paradigma que daría cabida a los planteamientos posestructuralistas, algunas corrientes del pensamiento posmoderno y diásporas paradigmáticas. En esta propuesta se sigue planteando la posibilidad de mantener la clasificación de los paradigmas ya reconocidos y adicionar uno más.

Pero los influjos del pensamiento posmoderno, en una visión más radical -con sus críticas destructoras a los metarrelatos-, junto con las ciencias y sus fundamentos epistemológicos nos obligan a preguntarnos: ¿es suficiente, incluso conveniente, la clasificación de tradiciones en la que se ha venido fundamentando la investigación educativa?, ¿puede pensarse la producción de conocimientos más allá de estos paradigmas?

La respuesta a estas preguntas nos lleva a reconocer la existencia de posicionamientos que trasgreden los marcos de clasificación paradigmática generados con el fin de dar orden al quehacer científico. Se puede pensar, por ejemplo, en los planteamientos de Boaventura de Sousa Santos (2009, p. 41), que -en el tránsito del siglo XX al XXI- invitan a pensar en una epistemología que va más allá de lo posmoderno. Inserto en lo que este autor considera una etapa de revolución científica perfila los componentes de un paradigma por emerger, al que Mignolo (2003) denomina un paradigma posmoderno oposicional, el cual está atento a las historias locales que emergen como espacios generadores de conocimientos y proyectos emancipadores ante la crisis de la modernidad europea. En su paradigma confluyen conocimiento de la naturaleza-conocimiento de lo social, conocimientos locales-conocimiento total; un conocimiento científico que reconoce su carácter autobiográfico y autorreferencial, susceptible de ser dialogado con otras formas del conocimiento, particularmente con la del sentido común en tanto esta hace posible el estar en el mundo.

De igual manera nos podemos acercar a lo que Restrepo y Rojas (2010) denominan inflexión decolonial, la cual "invoca una epistemología, un sujeto y un proyecto político que cuestiona los modelos eurocentristas del conocimiento y la agencia” (p. 22), en los cuales podríamos ubicar los cinco paradigmas señalados. Esta inflexión decolonial "antes que un nuevo paradigma (...) se considera un paradigma otro" (p. 22).

La afirmación anterior distancia a los teóricos decoloniales de los que podrían clasificarse como posmodernos -de acuerdo con Guba y Lincoln (2012)-, o como posmodernos oposicionales -de acuerdo con la denominación que asigna Mignolo a la propuesta de Santos (2003)-. El paradigmaotro asume que no puede ser incorporado junto con los otros en la clasificación, dado su carácter opositor al pensamiento eurocéntrico, afirmación que amplía los debates que se han generado en el ámbito académico sobre la coexistencia de paradigmas.

En el caso del paradigma otro propuesto por los autores decoloniales el propósito no es incluir un paradigma más, sino

cuestionar los criterios epistémicos de producción del conocimiento académico articulados al eurocentrismo y a la modernidad (...) consolidar un conocimiento no eurocéntrico y desde la herida colonial, es decir, un paradigma otro emergente desde la diferencia colonial (...) no es solo cambiar los contenidos sino también los términos y las condiciones de producción (...) labrar nuevas formas de análisis, no contribuir a los ya establecidos sistemas de pensamiento (Restrepo y Rojas, 2010, p. 20).

En este trabajo sostenemos que es posible encontrar elementos de confluencia no solo entre los paradigmas posmodernos reconocidos por Guba y Lincoln, (2012) como opuestos al positivismo (interpretativo, sociocrítico y participativo) -aquellos que han sido utilizados de manera convencional en el campo de la investigación educativa-, sino también con aquellos que asumen una crítica a posicionamientos eurocentristas y que han permanecido al margen de esta clasificación, como es el pensamiento decolonial. Se sostiene que el replanteamiento de la relación investigador e investigado es un asunto de interés común a ellos, dado que se orienta hacia la reconsideración del papel que tienen las personas que colaboran con el investigador. 
Con esto aludimos a la posibilidad de encontrar acercamientos entre los investigadores educativos que se alejan de los criterios positivistas de demarcación científica. Para ello, conviene recuperar aquí las palabras de Boaventura de Sousa Santos, con las que da respuesta a una crítica recibida de parte del teórico decolonial Walter Mignolo, para quien el distanciamiento con el pensamiento decolonial se establece cuando el primero plantea un paradigma de transición y no uno de disrupción:

dada la grandeza de los desafíos que se nos colocan, pienso que sería más correcto adoptar estrategias teóricas que profundicen las alianzas en lugar de estrategias que fragilicen al insistir en la diferencia descalificadora - y al final tan moderna- entre "nosotros" y "ellos". De cara a las relaciones de dominación y de explotación, profundas y de larga duración, que la modernidad occidental capitalista instauró globalmente, debemos centrarnos en la diferencia entre opresores y oprimidos y no en la diferencia entre los que, desde varias perspectivas y lugares, luchan contra la opresión (Santos 2009 citado en Restrepo y Rojas, 2010).

La cita anterior nos conmina a encontrar puntos de confluencia que hagan posible avanzar en los procesos de generación de conocimientos desde planteamientos no positivistas; uno de estos aspectos es precisamente la relación que se establece entre el investigador y el investigado, componente que nos invita a pensar en el cómo ser y cómo estar en la investigación.

\section{CóMO SER Y ESTAR EN LA INVESTIGACIÓN}

Los replanteamientos con respecto de la relación investigador e investigado en la investigación educativa nos llevan a refrendar la figura del coinvestigador. Esta propuesta de denominación se aleja del paradigma positivista, que por mucho tiempo colonizó el modo de producción de conocimientos científicos, en busca tanto de la objetividad, de la totalización y de la universalidad, como de la determinación de explicaciones de tipo causal a partir de metodologías cuantitativas y un razonamiento lógico deductivo.

En el paradigma positivista el investigado ha sido reducido a simple objeto de conocimiento, o como proveedor de información (informante). Esta mirada instrumental coloca al investigador en una posición de poder y control respecto a sus informantes de los que se debe mantener alejado. Este posicionamiento del investigador dificulta recuperar el carácter humano de aquellos a quienes investiga e impide comprender las trasformaciones que él mismo sufre durante el proceso de investigación.

Contrario a este paradigma, aquí se asume que, en la investigación educativa que pretende la comprensión de los procesos intersubjetivos situados regionalmente, que crean y recrean relaciones de diversa índole en el devenir de la vida cotidiana, es necesario que el investigador atienda a los sentidos y significados que construye a partir de la relación que establece con las personas con quienes se involucra durante el proceso de indagación, destacando la dimensión cualitativa que se orienta "hacia una comprensión particular, en contraste con la investigación cuantitativa que se dirige a una comprensión general” (Willis citado en Pinar, 2014).

En ocasiones se discute el papel del investigador atendiendo a los elementos metodológicos que guían su proceder. Estos análisis tienden a centrarse en el habitus del investigador, para destacar el carácter técnico de la relación que establece con sus informantes, a través de técnicas e instrumentos de recolección de información, soslayando las dimensiones de poder, saber e influencia involucrados en dicha relación. Frente a esto, hay quienes plantean que es necesario tener en cuenta que "es la desigualdad del poder y del saber la que transforma la reciprocidad del descubrimiento en apropiación del descubierto. En este sentido, todo descubrimiento tiene algo de imperial, es una acción de control y sumisión” (Santos, 2003, p. 69). De ahí que sea importante reflexionar acerca de la relación investigador-investigado desde una perspectiva distinta.

De acuerdo con Godinho "quien descubre es también descubierto" (Santos, 2003, p. 69). Con estas palabras queremos evidenciar la transformación que sufre el investigador que se acerca con una mente abierta, dispuesta a dialogar con las personas. Este acercamiento está marcado por el posicionamiento paradigmático del investigador (epistemológico, político, axiológico, ético/moral, social y biográfico) que lo expone y lo descubre ante los otros. 
Se ha hablado sobre el conocimiento y saber colonial/hegemónico que el investigador construye y desde el cual se nombra a los otros pero es necesario tener en cuenta el papel bidireccional y de influencia mutua que se construye entre investigador e investigado; ambos como actores sociales que se relacionan, se afectan y se coconstruyen.

Esta manera de ser y estar en la investigación, misma que nos aleja del positivismo, nos acerca a los paradigmas interpretativo, sociocrítico y participativo, así como a formas alternas de pensar el conocimiento desde el paradigma posmoderno transicional o desde el pensamiento decolonial, lo que provoca la siguiente pregunta: ¿Hasta dónde son compatibles los criterios que establecen al plantear la relación investigador e investigado? La respuesta a esta pregunta es afirmativa solo si las tradiciones o

modelos (paradigmas) comparten elementos axiomáticos que son similares, o que resuenan de modo potente entre ellos. Entonces, por ejemplo, el positivismo y el pospositivismo son claramente conmensurables. Asimismo, los elementos de la teoría crítica interpretativista/posmoderna, la investigación constructivista y participativa, encajan con comodidad. La conmensurabilidad constituye un problema solo cuando los investigadores quieren escoger y elegir entre los axiomas de los modelos positivista e interpretativista, porque esos axiomas son contradictorios y mutuamente excluyentes (Guba y Lincoln, 2012, p. 51).

Con base en esta afirmación se propone revisar la forma en la que diversos autores, que se ubican en alguna tradición no empírico-analítica (fuera del paradigma positivista), han replanteado la relación que se establece entre investigador e investigado, sosteniendo que sus planteamientos confluyen en la imagen de la coinvestigación. Esto es, en la necesidad de pensar que son las interacciones que realizan investigador e investigado las que hacen posible la construcción del conocimiento, lo que rompe con la idea de la separación sujeto-objeto de conocimiento.

Bruner (1997) propone un análisis de tipo hermenéutico, desde el cual se realizan lecturas multirreferenciales y multidireccionales entre investigador e investigado, ya que:

ninguna historia tiene una interpretación única. Sus significados imputables son en principio múltiples. No hay ni un procedimiento racional para determinar si una lectura en particular es necesaria como son necesarias las verdades lógicas, ni un método empírico para verificar cualquier lectura concreta. El objetivo del análisis hermenéutico es aportar una explicación convincente y no contradictoria de lo que significa un relato, una lectura que se atenga a los detalles particulares que la constituyen. Esto genera el famoso círculo hermenéutico [entre investigador e investigados, bidireccional y multirreferencial/multidireccional]: intentar justificar la "adecuación" de una lectura de un texto, no por referencia al mundo observable o las leyes de la razón necesaria, sino por referencia a otras lecturas alternativas (...) allá donde las expresiones solo tienen sentido o no en relación con otras (pp. 158-159).

Desde la autoetnografía, Chang (2008) reconoce la influencia y el acompañamiento mutuo como condiciones que marcan la relación del investigador y el investigado, en tanto ambos coconstruyen, resignifican y deconstruyen sus decisiones y posicionamientos, lo que propicia reflexiones de transformación y cambio. Para responder al siguiente cuestionamiento: ¿cómo la influencia del investigado regresa al investigador y viceversa?, la autoetnografía:

enfatiza el análisis cultural y la interpretación de los comportamientos de los investigadores, de sus pensamientos y experiencias de indagación, habitualmente a partir del trabajo de campo, en relación con los otros y con la sociedad estudiada. Es lo que algunos autores explican en diferentes trabajos sobre este género de etnografía como la exploración de la interacción entre el yo personal y lo social o entre el ser introspectivo y lo cultural, esto es, la observación y la descripción detenida y en profundidad de la conexión entre lo personal y cultural (Guerrero, 2014, p. 238).

En la investigación de corte interpretativo-crítico, a partir de un método narrativo Espinosa (2015) se propone relacionar lo humano con lo social y lo político, reconociendo la presencia de aquello que la ciencia moderna ocultó de lo humano, la dimensión afectiva del acto educativo. Afirma que las emociones y sentimientos que se involucran en los procesos de indagación son los que acompañan, componen, contaminan (Flores Martos, 2010) y dan sentido al ser y estar en la investigación; éstas se traducen en dominios de acciones (Maturana, 2001) para los sujetos involucrados. Estos dominios se manifiestan en un 
permanente conocimiento/descubrimiento, durante el trabajo de campo, durante la reflexión/interpretación de datos, la redacción, la edición y la comunicación de los resultados de la investigación, esclareciendo y/o dificultando las miradas del investigador. Las emociones, los sentimientos, al entrar en relación, influyen en el acto interpretativo y formativo del investigador y del investigado. En este tipo de investigación, la narración

no pertenece ni al narrador ni al narratario (...) ambos realizan un aporte característico desde su posición, contribuyendo con una parte, complementándose (...) Estos desplazamientos recíprocos e inversos (de distanciamiento teórico e implicación práctica) permiten la creación de un espacio y de un sistema de comunicación, de una nueva unidad (...) el narrador no es el único que habla, piensa y se transforma (...) el narratario también está en juego al momento de recoger o analizar un relato, investigar desde este enfoque implica conocer al precio de ser conocido (Cornejo, Mendoza, Rojas, 2008, pp. 31-32).

En un acercamiento a la tradición sociocrítica clásica, la explicación que ofrece Gramsci sobre el rapport pedagógico entre intelectuales y trabajadores puede ser trasladada para comprender la influencia mutua que se establece entre investigador e investigado:

Paso del saber al comprender, al sentir y viceversa, del sentir al comprender, al saber. El elemento popular siente, pero no siempre comprende y sabe; el elemento intelectual sabe, pero no siempre comprende y especialmente siente. Los dos extremos son, por tanto, la pedantería y el filisteísmo de una parte y la pasión ciega y el sectarismo de la otra (...) en ausencia de tal nexo, las relaciones del intelectual con el pueblo-nación son o se reducen a relación de orden puramente burocrático, formal; los intelectuales se convierten en una casta o un sacerdocio (denominado centralismo orgánico). Si la relación entre intelectuales y pueblo-nación, entre dirigentes y dirigidos -entre gobernantes y gobernados- está dada por una adhesión orgánica en la que el sentimiento-pasión deviene comprensión y por tanto saber (no de un modo mecánico, sino viviente), solo entonces se da una relación de representación, y se produce el intercambio de elementos individuales entre gobernantes y gobernados, entre dirigentes y dirigidos, esto es, se realiza la vida de conjunto que es, exclusivamente, la fuerza social; se crea el bloque bistórico (2001, pp. 346-347).

La propuesta dialógica de Freire (1974) fortalece este planteamiento, así como las propuestas de la investigación-acción, que convencionalmente se ubican en una tradición sociocrítica e involucran activamente al investigado comprometiéndolo con el saber, con el hacer, con el ser, con la participación y la acción para el desarrollo de una conciencia crítica que conduzca a la transformación, de manera que:

los sujetos investigados son auténticos coinvestigadores participando muy activamente en el planteamiento del problema a ser investigado (que será algo que les afecta e interesa profundamente), la información que debe obtenerse al respecto, los métodos y técnicas a ser utilizados, el análisis e interpretación de los datos, la decisión de qué hacer con los resultados y qué acciones se programaran para su futuro. El investigador actúa esencialmente como un organizador de las discusiones, como un facilitador del proceso, como un catalizador de problemas y conflictos, y, en general, como un técnico y recurso disponible para ser consultado (Martínez, 2000, p. 28).

Podemos también ubicarnos en un paradigma emergente a la manera en que lo propone Boaventura de Sousa Santos (2009, pp. 53-54), en busca de "un conocimiento comprensivo e íntimo que no nos separe y antes bien nos una personalmente a lo que estudiamos (...) [al] entendimiento de un mundo que más que controlado ha de ser contemplado". Para ello se ensayan posicionamientos posmodernos que suponen una traducción intercultural y hermenéutica diatópica, la primera, al "crear inteligibilidad recíproca entre las experiencias del mundo, tanto las disponibles como las posibles” (Santos, 2010, p. 52), y la segunda:

consiste en un trabajo de interpretación entre dos o más culturas con el objetivo de identificar preocupaciones isomórficas entre ellas, y las diferentes respuestas que proporcionan (...) la hermenéutica diatópica parte de la idea de que todas las culturas son incompletas y, por tanto, pueden ser enriquecidas con el diálogo y por la confrontación con otras culturas (Santos, 2010, pp. 53-55).

Desde el pensamiento decolonial también se presentan rasgos que pretenden resarcir la añeja escisión entre investigador e investigado, así como las perspectivas instauradas tradicionalmente en la relación del sujetoobjeto de indagación. Mignolo (2003) señala: 
el prejuicio que asume la superioridad de ciertos conocimientos sobre otros es un escollo que ha de superarse desde ambas perspectivas del espectro: por quienes trabajan en las oficinas del saber superior [en este caso aludimos a los investigadores instalados en la academia tradicional] y por quienes trabajan en las oficinas del saber subalterno [refiriéndonos a los sujetos que buscan posicionamiento alternativos, pero también a quienes habitan y construyen su mundo de vida en la realidad estudiada] (pp. 21-22).

En este proceder tradicional del investigador se cuestiona la práctica que realiza desde la colonialidad del saber (Walsh, 2007; Lander, 2010), por la cual el investigador asume planteamientos jerárquicos y de poder que posicionan al occidente europeo como único generador de conocimiento(s), desestimando otras lógicas de producción/apropiación/aplicación del mismo.

En los casos referidos antes, lo que se propone es un replanteamiento de la relación entre investigador e investigado, asumiendo posiciones teórico-metodológicas diversas (hermenéuticas, autoetnográficas, narrativas, críticas o de investigación-acción, posmodernas y decoloniales) que se ubican en los paradigmas o tradiciones interpretativa, sociocrítica, participativa, así como en la crítica posmoderna o decolonial. Ellas nos llevan a proponer la figura de coinvestigadores para referirnos a las personas con quienes se involucra el investigador educativo para comprender el mundo, que es, a fin de cuentas, su mundo.

\section{Hacia la denOMinación de COINVESTIGadores}

¿Qué implica aceptar la presencia de coinvestigadores e incluso nombrarlos como tales en una investigación y en los productos de esta?

En primer lugar, se reconoce la existencia de una relación profunda, dialógica y dialéctica, incluso afectiva, que toca a investigador e investigado en distintos sentidos, con miras a la construcción de un conocimiento compartido. Estos procesos de construcción compartida se sostienen en las experiencias vividas por cada uno en diferentes contextos socioculturales, momentos históricos, políticos e intereses diversos, y se corresponden con un componente fenomenológico valioso, que aflora a partir del encuentro. Este componente se manifiesta de múltiples maneras en las relaciones que establecen, en las palabras, en las pausas, en los silencios, en las marchas y contramarchas que se dan rumbo a la acción interpretativa y que permiten la comprensión del ser y estar en la investigación.

En segundo lugar, se admite la incorporación de la reflexividad como una práctica del investigador, que admite la presencia de una dimensión axiológica en el quehacer investigativo, la cual rebasa las miradas técnicas del proceder científico, que se centran en los procedimientos metodológicos como reglas a seguir de manera acrítica. La reflexividad se presenta cuando el investigador se cuestiona sobre la manera en que mira, se acerca, interviene, atiende, interpreta y/o detona transformaciones en la realidad. También como un ejercicio que el investigador promueve con las personas que habitan el mundo que pretende comprender y sobre las implicaciones de la investigación en ese mundo.

Entender la investigación educativa como un proceso que conlleva en sí mismo la reflexividad obliga a reconocer un papel activo de parte de los coinvestigadores, quienes afectan, influyen, guían, restringen o potencian las posibilidades de hacer la investigación y de tomar decisiones en el contexto, porque el investigador no es el mismo en cada contexto que recorre, es él en función del/los coinvestigador(es).

En tercer lugar, se asume que toda investigación es singular, dado que las experiencias vividas entre investigador e investigados, sus encuentros y desencuentros son los que definen las posibilidades de alcanzar o replantear los objetivos trazados. Las maneras de relacionarse con los coinvestigadores, de ser y estar en la indagación, son particulares y se vinculan/vehiculan directamente a partir de la subjetividad del/los otro(s), siempre que se admita que "el investigador y la investigadora son sujetos que cuando investigan sobre otros y otras están investigando sobre sí mismos y sí mismas” (Cortés y Nuñez, 2012, p. 229).

En cuarto lugar, se establece un compromiso con el cambio y la transformación de la realidad regional a la que el investigador se aproxima y en la que permanece investigando. Específicamente, en el ámbito 
educativo, la investigación es un acontecimiento vinculado a la noción de práctica reflexiva, a partir de la cual los profesores, estudiantes y demás actores educativos modelan un proceso social que les permite tomar consciencia de su acción y desde allí mejorar su praxis pedagógica (Elliot, 1993; Schön, 1998).

Desde estas consideraciones, el compromiso lleva a considerar como parte de la investigación educativa la devolución de los resultados. En este sentido Rivas y Leite (2011) proponen crear vínculos colaborativos y democráticos con los investigados, reconocerlos como autores de la interpretación de su propia vida y promover procesos de devolución en distintos sentidos: individual y grupal, en el contexto de indagación y fuera de él, involucrando diferentes actores, y desbordando los fines del reporte o informe técnico de investigación.

\section{CoNCLUSIÓN}

Colocados en una tradición de investigación opuesta a la empírico-analítica, sea que nos reconozcamos como investigadores educativos interpretativos, sociocríticos, participativos, posmodernos o decoloniales (lo que incluye también la posibilidad de rehusar identificarnos o etiquetarnos en alguna de las tradiciones señaladas), la comprensión profunda de la relación que se establece entre investigador e investigado nos lleva a plantear la figura de los coinvestigadores como protagonistas de la investigación, que influyen significativamente en la toma de decisiones del investigador educativo, en la interpretación de la información, en sus resultados y en las acciones de cambio, transformación o mejora.

A partir de esta se detonan procesos de investigación educativa que pueden tender a la comprensión y entendimiento de los otros y del propio investigador, a la acción, transformación y cambio de las relaciones que priman en la sociedad o grupo social con el que se investiga, a la expresión de una realidad construida a partir de múltiples voces que irrumpen y se hacen visibles, al develamiento de discursos y la deconstrucción de saberes dominantes.

Al ubicarnos como investigadores educativos interesados en comprender, recuperar voces silenciadas, contribuir en procesos de transformación, develar intereses o analizar discursos de poder, dependemos de aquellos que nos acompañan en el proceso de indagación, para quienes, suponemos, los resultados de nuestras investigaciones podrían resultar valiosos. Ellos asumen un papel de coinvestigadores en el sentido expuesto a lo largo del escrito.

Como se ha hecho evidente en este artículo, este replanteamiento no es exclusivo de un paradigma o tradición de investigación, ni de un posicionamiento teórico-metodológico particular, sino que emerge como una preocupación compartida por los investigadores que siguen lógicas de construcción de conocimientos que trasgreden la empírico-analítica propia del paradigma positivista. Estos investigadores están dispuestos, al momento de relacionarse con las personas involucradas en el proceso de indagación, a reconocer la influencia recíproca investigador-investigado que marca al proceso de investigación. El reconocimiento y la denominación de coinvestigadores en el campo de las ciencias sociales y humanas, y particularmente en el de la investigación educativa, atiza los debates en torno al papel del/los investigados y potencia las posibilidades de transformación en el contexto cuando, en un ejercicio crítico y consciente, asumen el compromiso de transformar su realidad educativa a partir de su propia organización y acción.

Asumir esta denominación en la investigación educativa es acorde con un proceso de construcción, generación y aplicación del conocimiento creativo, democrático, multiactoral y plurimetodológico que favorece la participación.

\section{REFERENCIAS}

Acosta, F. (2005). ¿Sabes realmente qué es un paradigma? Revista Iberoamericana de Educación, 34(5), 1-10. Recuperado de http://rieoei.org/fil_edu6.htm 
Bruner, J. (1997). La educación, puerta de la cultura. Madrid: Machado.

Chang, H. (2008). Autoetnography as method. Walnut Creek: Left Coast Press.

Cornejo, M.; Mendoza, F., y Rojas, R. C. (2008). La investigación con relatos de vida: pistas y opciones del diseño metodológico. Psykhe, 17(1), 29-39. Recuperado de http://www.psykhe.cl/index.php/psykhe/article/view/18 $9 / 186$

Cortés, P., y Núñez, C. (2012). El sujeto que investiga el sujeto investigado. En J. I. Rivas et al. (Coord.). Historias de vida en educación. Sujeto, diálogo y experiencia (pp. 227-231). Barcelona: Dipòsit Digital UB. Universidad de Barcelona: Red Universitaria de Investigación e Innovación Educativa. Recuperado de http://hdl.handle.net/ $2445 / 32345$

Elliott, J. (1993). Reconstructing Teacher Education. London: The Falmer Press.

Espinosa, I. J. (2015). La escuela habitada. Experiencias escolares, pensamiento critico y transformación social en una región intercultural (Tesis doctoral). Recuperado de http://hdl.handle.net/10630/11511

Flores, J. A. (2010). Trabajo de campo etnográfico y gestión emocional: notas epistemológicas y metodológicas. Ankulegi, 14, 11-23. Recuperado de https://aldizkaria.ankulegi.org/index.php/ankulegi/article/view/22

Freire, P. (1974). Pedagogía del oprimido. México, DF: Siglo veintiuno editores.

González, F. (2005). ¿Qué es un paradigma? Análisis teórico, conceptual y psicolingüístico del término. Investigación y postgrado, 20(1) 13-54. Recuperado de https://www.redalyc.org/articulo.oa?id=65820102

Gramsci, A. (2001). Cuadernos de la cárcel, tomo IV. México: Era ediciones.

Guba, E., y Lincoln, Y. (2012). Controversias paradigmáticas, contradicciones y confluencias emergentes. En N. Denzin y Y. Lincoln (Coord.), Paradigmas y perspectivas en disputa. Manual de investigación cualitativa (Vol. II, pp. 38-78). Barcelona: Gedisa.

Guerrero, J. (2014). El valor de la auto-etnografía como fuente para la investigación social: del método a la narrativa. Azarbe, 3, 237-242. Recuperado de https://revistas.um.es/azarbe/article/view/198691

Habermas, J. (1990). Conocimiento e interés. Buenos Aires: Taurus.

Kuhn, T. S. (2004). La estructura de las revoluciones cientificas. Argentina: Fondo de Cultura Económica.

Lander, E. (2000). Ciencias sociales: saberes coloniales y eurocéntrico. En La colonialidad del saber: eurocentrismo y ciencias sociales. Perspectivas latinoamericanas (pp. 4-23). Buenos Aires: Clacso. Recuperado de http://bibliotec avirtual.clacso.org.ar/clacso/sur-sur/20100708034410/lander.pdf

Martínez, M. (2000). La investigación-acción en el aula. Agenda académica, 7(1), 27-39. Recuperado de http://files. docentia.webnode.es/200000031-e2181e310b/ia.pdf

Mignolo, W. D. (2003). Historias locales/diseños globales. Colonialidad, conocimientos subalternos y pensamiento fronterizo. Madrid: Akal.

Pinar, W. F. (2014). La teoría del curriculum. Madrid: Narcea.

Pons, L. y Hernández, N. L. (2012). En torno a los debates epistemológicos y paradigmas. En L. Pons, et al. (Coord.) El protocolo de investigación. Enfoques, métodos y técnicas en ciencias sociales y humanas (pp. 41-96). Tuxtla Gutiérrez: Universidad Autónoma de Chiapas- CecoI.

Restrepo, E., y Rojas, A. (2010). La inflexión decolonial. Fuentes, conceptos y cuestionamientos. Colombia: editorial Universidad del Cauca.

Rivas, J. I. y Leite, A. E. (2011). La devolución en los procesos de construcción interactiva de los relatos. En F. Hernández, J. Sancho y J. I. Rivas (Coord), Historias de vida en educación biografias en contexto (pp. 75-80). Barcelona: Universitat de Barcelona-Esbrina-Recerca. Recuperado de http://diposit.ub.edu/dspace/bitstream/2445/15323/7/Historias\%20de\%20vida\%20en\%20Educaci\%C3 \%B3n.\%20Biografias\%20en\%20contexto.pdf

Schön, D. A. (1998). El profesional reflexivo. Cómo piensan los profesionales cuando actúan. Barcelona: Paidós Ibérica. Sandín, M. P. (2004). Investigación cualitativa en educación. Fundamentos y tradiciones. Madrid: McGraw Hill.

Santos, B. S. (2003). La caida del angelus novus: ensayos para una nueva teoría social y una nueva práctica política. Bogota: Antropos ltda-ILSA. 
Leticia Pons Bonals, et al. Protagonistas de la investigación educativa. Investigador-investigado ...

Santos, B. S. (2009). Una epistemología del Sur. México: CLACSO-Siglo XXI.

Santos, B. S. (2010). Refundación del Estado en América Latina: perspectivas desde una epistemología del Sur. México: Siglo XXI.

Walsh, C. (2007). ¿Son posibles unas ciencias sociales/culturales otras? Reflexiones en torno a las epistemologías decoloniales. Nómadas, 26, 102-113. Recuperado de http://www.redalyc.org/articulo.oa?id=105115241011

\section{BY-NC-SA}

